\title{
AGRADECIMENTO DO PROFESSOR CARLOS DA SILVA LACAZ *
}

Ao receber, nesta manhã, gratificante homenagem dos colegas, amigos e funcionários da Escola de Enfermagem, a que ligam laços de velha e indefectível admiração, elevo inicialmente meu pensamento a Deus, a quem agradeço por me ter concedido tantas graças, fazendo-me suportar o êxito com humildade, a afeição dos amigos sem vanglória e, ainda, a uma fortaleza de ânimo que me preparasse para enfrentar com dignidade as horas de angústia e de provação.

Desambicioso de honrarias, porque em tudo sei pesar o relativo das coisas e o transitório dos juízos humanos - "Os barulhos da vida desaguam sempre no silêncio do tempo", agradeço comovido à Profa. Leda Ulson Mattos, digníssima Diretoria da Escola de Enfermagem, tão elevada distinção que me foi conferida.

Posso afirmar, sem falsa modéstia, que como médico, cidadão e professor, meus passos se viram sempre cercados por uma constante atmosfera de simpatia e de incitamento que a minha produtividade científica e ação na comunidade estão muito longe de justificar. Tenho usufruído da vida muito mais do que me era lícito esperar, mesmo dentro das raias da mais desenfreada ambição. Voltado exclusivamente para o estudo e a família, tenho a consciência do dever cumprido e recebo esta homenagem com o mesmo sentimento de humildade que sempre dominou os meus atos. A Medicina aproxima-nos das verdades fundamentais da Natureza e nos põe em contato com o precário e o fugitivo de todas as coisas e com a realidade tangível da morte. O convívio permanente com os dados da ciência experimental conduziu-nos sempre a uma atitude de compreensão e, também, de humildade. Claude Bernard, que traçou o roteiro da ciência experimental, disse com a consciência de suas responsabilidades que, instruindo o homem, a ciência tem por efeito diminuir-lhe cada vez mais o orgulho, provando-lhe todos os dias que as causas primeiras, bem como a realidade objetiva das mesmas lhe serão para todo o sempre ocultas, dela não podendo conhecer senão as relações. As noções ainda as mais solidamente demonstradas, encerram apenas uma parcela da verdade. No entanto, é clara a tarefa dos homens de ciência. E marchar para a frente, sem que os detenham quaisquer incertezas. A fé na ciência não é incompativel com qualquer outro tipo de fé, nem a exclui. Na verdade, parece não haver incoerência em crer que o conhecimento científico seja, em si mesmo, um dos grandes instrumentos para fins mais elevados.

- Discurso pronunciado na srscola de Innfermagem da USP, no dia 12 de junho de 1985. 
Seja como for, a aptidão e o gosto pela vida unem suas vozes, reclamando esforços incansáveis, não só com certeza, mas com esperança e fé em que possa o conhecimento avançar, aumentar o domínio sobre todos os males sociais, ser abolido o trabalho escravizante, curadas as enfermidades, alimentando o povo, tornando a vida mais feliz. Enquanto os velhos têm sonhos e os jovens vêm visões, devemos ir para frente sem vacilar, a fim de que os sonhos possam tornar-se realidade e as visões se concretizem. Enfim, cada um deve fazer o que puder para diminuir a soma total da desgraça humana.

Ao final de minha carreira, continuo a sentir, cada vez mais, a grandeza de Deus ao criar esta coisa prodigiosa que é o corpo humano. No crescimento, no milagre da adolescência, na saúde plena e na euritmia da idade madura, na vida em toda a sua pujança e o seu transbordamento na reprodução. Igualmente admirável nos desequilíbrios da velhice, na senectude, na desagregação e, até na própria morte. Nós, pobres doutores que somos, só podemos quando muito, alterar e modificar a vida pelo ferro cirúrgico ou, então, pelo veneno remédio, procurando que a alteração introduzida esteja sempre, no caminho da vix medicatrix naturae. Je pense, Dieu guerit, dizia humildamente Ambroise Paré, o pai da cirurgia. Prolongando a vida por alteração de condições, não estamos combatendo a morte. Estamos, apenas, ampliando vida que existe. O que temos, então, é de nos convencer de que o homem, de tanto viver e o doente, de tanto padecer - adquirem o direito à morte, tão respeitável como o direito à vida, por parte de quem nasceu.

Lembro-me bem que nos idos de 1943 aqui entrava para lecionar Microbiologia e Imunologia às alunas desta Escola, na época diŕigida por D. Edith de Magalhães Fraenkel, excelsa figura de mulher e que, de 1941 e 1955 exerceu com elevado zelo e dignidade aquela função.

Era um prazer enorme lecionar àquelas jovens cuja simpatia se irradiava pelas paredes desta Casa, com festas e bailes a que eu sempre comparecia, vivendo uma época das mais belas de minha vida. Em 1946 diplomava-se a $1^{\text {a }}$ Turma e eu continuava a exercer o magistério, por 10 anos consecutivos.

Mais tarde, já na maturidade da vida, após ter exercido o cargo de Diretor da Faculdade de Medicina (1914-1978), honrou-me o Reitor Waldir Muniz Oliva - com a designação para dirigir a Escola de Enfermagem, de 1978 a 1982, sucedendo a Profa. Maria Rosa Sousa Pinheiro (1955-1978).

De todos, professores, alunos e pessoal técnico-administrativo recebi e continuo a receber as mais calorosas manifestaçōes de simpatia e apreço, a permanente voz do amor, imutável. Ela me faz sentir o esplendor da verdadeira amizade e por ela interpreto o Eclesiástico, quando no intróito proclamou: Bemaventurado o que achou o amigo verdadeiro. Eu o encontrei em cada um de vós, como se fosse a própria formosura de Deus reverberada na criatura humana.

Diz uma oração que este mundo é um oceano de amargura, não valendo a pena viver nadando eternamente, a romper com o peito as 
ondas do mar revolto. O melhor seria que ficássemos cada um construindo pacientemente o seu batel. Depois, soltem-se os remos e vagaremos serenamente à flor das águas, a ver a asa das gaivotas cortando o azul do céu.

Minha vida, porém, foi sempre feita de árduas lutas. Na minha caminhada forjei o meu espirito e fortifiquei o meu coração, procurando seguir o exemplo de meu pai, educador de raros méritos, consubstanciados na dedicação ao trabalho que tudo vence, no culto à minha religião, no amor à minha terra e à minha família e na prática da caridade. O trabalho útil, decididamente encetado e seguido com constância reanimou as forças do meu espirito; o sentimento religioso trouxe-me a fé, a coragem e o consolo para as horas dificeis, no labor de todos os dias, inspirando-me também paciência, resignação e tolerância para com o próximo. A caridade, exercida para com os outros, suavizou as dores de muitos, consolando-os no alívio de seus males.

A vida, meus caros colegas e amigos, é antes e acima de tudo, o instrumento do bem que os homens se devem uns aos outros. Esta é uma reunião de aproximação, uma bela mensagem de fraternidade, no mundo conturbado em que vivemos, numa humanidade em crise - crise de ideais, de humanismo e de valores morais. A solução para todos os problemàs do mundo deverá estar regulada por uma força moral que se fundamente no caráter do homem, nutrida pelas verdades eternas de Deus. A civilização atual só permanecerá se o homem moderno dirigir o poder material de sua ciência pelas verdades espirituais do seu Criador. Mais do que nunca, deve-se procurar um novo humanismo, que saiba conciliar a visão clássica dos valores da subjetividade com as exigências objetivas da ciência contemporânea. Só desta maneira poderemos dar algum valor e sentido à vida humana, nesta escura debandada para o nada.

Nesta cerimônia, evoco as figuras marcantes de Ana Neri, a baiana ilustre, precursora entre nós da $\mathrm{Cruz}$ Vermelha Brasileira e que, no campo das batalhas, na guerra do Paraguai, acudia aos feridos com indômita coragem e admirável solicitude.

Todos vós conheceis, também, a vida gloriosa de Florence Nightingale, verdadeira heroina do bem e que, nascida na velha e doce Itália, estudou Medicina e Enfermagem nos hospitais de Londres e de Edinburgo, preparando-lhe o aprendizado do rigor da disciplina hospitalar. Longefellow, o grande poeta norte-americano, exaltou-a em "Filomena", versos que percorreram todo o mundo. Famosas, são também, as figuras de Edith Louisa Cavell, a heroína da guerra de 1914 e de Genevieve de Gallard, a qual em Diehl Bien Phu, na Indochina, resistiu em fortim, às forças inimigas, cumprindo seu dever de enfermeira até o final.

As enfermeiras são os anjos tutelares dos médicos, na eterna luta do homem contra a doença e contra a morte. Elas devem possuir, pela sua própria formação, uma sublimidade de intenções que só os predestinados pelo amor ao próximo conseguem realizar. Cristo, na parábola 
do bom samaritano, demarcou bem o sentido do amor ao próximo, o único verdadeiro. Descia um homem de Jerusalém, para Jericó, quando, no seu caminho, malfeitores o pilharam e o agrediram, deixando-o entre a vida e a morte. Passou um religioso e não deu tento dele; depois, um levita e nem sequer o olhou; mais tarde, passou um samaritano, pensou-lhe as feridas com óleo e vinho, levou-o a uma hospedaria à sua garupa, tomando-lhe os cuidados de cura. Se o tivesse acudido apenas com dinheiro ou palavras, não teria exercido por completo o seu dever humano, nem o seu ato teria uma significação de bondade ativa. A enfermeira é, na realidade, o anjo custódio do doente.

Sublime foi a missão concedida à mulher, quando Deus lhe confiou, além da função da maternidade, a de aliviar o sofrimento humano. Poucos são os homens que se nutrem desse entranhado amor ao próximo, na função apostolar de semear e de praticar o bem, a de ser o irmão de seu irmão, como essa extraordinária figura de Alberto Schweitzer, um dos grandes organistas da Europa, intérprete e biógrafo de Bach, que tudo abandonou na Europa para em Lambarène, na antiga África Francesa, tratar dos pobres pretos entregues a doenças de toda a natureza e a devastações da miséria física.

A humanidade vive hoje sob o signo da técnica, sob o esplendor das conquistas materiais, sob o crescente mundo da ciência e, paradoxalmente, em contrapartida, da maré montante da violência organizada, da escalada das tragédias e das mortandades, na dança do ódio, do desespero e da destruição dos valores fundamentais do homem e do convivio civil.

Assistimos, estarrecidos, à contestação frontal e impiedosa, primeiro ao mundo axiológico sob o qual se estruturaram as mais progressistas nações e floresceram as civilizações informadas de cultura e de humanismo e, depois, nos dias que correm, ao desafio aberto, diuturno, crescente, sangrento, das mais variadas formas de violência, traduzidas em atentados, em crimes de sequestros, pirataria aérea e maritima, em banhos de sangue, num atestado eloquente do naufrágio da própria ciência, do império do Direito e da falência das condições necessárias da comunhão humana.

Este fenômeno do desamor e da brutalidade, do desespero e do sangue, estende-se a todos os quadrantes do mundo, divide os próprios irmãos, golpeia as mais antigas instituições jurídicas, rastreia de ódio as próprias religiões e parece resumir, como numa cena apocalíptica, o epilogo irreversivel da derrota final do próprio homem. "A hora é horizontal como um réptil. Escura, como noite invernosa. Traiçoeira como areia movedica. Como J6, clamamos todos pela aurora".

René Le Senne, pensador francês, em sua "Introdução à Filosofia", evidencia num retrato profundo e severo, as raízes da crise contemporânea. O homem do fim do século XIX fundou suas esperanças na ciência, que faria da Terra um novo Eden, sob a garantia do império do Direito, que estabeleceria definitivamente a paz e a justiça.

A ciência, infelizmente, mostrou seu poder maior pelo próprio poder de destruição, da mesma forma que o jurista deve ser levado a inter- 
rogar sobre a relação entre o Direito, a existência e o valor, quando se convencer que a ordem jurídica é, em si mesma, destituída da força de que precisa para se impor e vingar.

Haveremos de encontrar os itinerários da paz e da ordem social, superando obstáculos ou gravames.

Não admitimos que o Homem seja reduzido a um produto da História, objeto do Estado, transitória personagem de uma moldura vinculada apenas às propriedades espaço-tempo. $E$ isto porque, cada ser humano se reveste de um conteúdo ético; ele é a expressão de um mundo de valores eternos, estruturado no mistério de sua origem divina e de sua destinação metafísica.

O Homem-econômico, o Homem-massa surgiu sob as forças de uma sociedade de consumo, alienado à luz da História, despido de seus valores absolutos.

Michelet, notável historiador francês, disse num estudo profundo das Catedrais da Idade Média que, naquela época, o Templo era a Casa do Povo. Em seu recinto surgiu o direito de asilo, e os sinos, sonoros ou tristes, chamavam o povo, para as grandes deliberações, as festas gloriosas ou os momentos de grave tristeza. Só o amor solidário será, ainda e sempre, o sentimento redentor de um "bicho da terra tão pequeno", como o pôs em verso e gênio maior de nossa língua. Aliás, tenho dito que, no santuário da Medicina, o mal e a maldade não têm guarida e, se o médico comporta-se como o homem de nossos dias e prejudica ao seu próximo, deixa de ser médico para converter-se em um delinqüente comum.

Nesta hora de tantas apreensões, vivendo nossa Medicina crise das mais sérias, precisamos espiritualizar cada vez mais a nossa profissão, servindo ao doente em todas as horas, nunca se esquecendo, sob qualquer pretexto, os valores transcendentais da assistência ao que sofre, preservando a honorabilidade da Medicina, penhor seguro de tranqüilidade e de segurança nacional. O médico é um profissional que trata de vidas humanas e não de valores econômicos.

Já ao final de uma longa carreira docente, vivendo em contato permanente com a dor e o sofrimento humano, faço nesta sessão uma verdadeira "declaração de princípios", sem qualquer intuito demagógico. Vivemos, indiscutivelmente, uma hora dramática da humanidade, com a transmutação radical e repentina de todos os valores tradicionais. Já o anunciara Friederich Nietzche, há mais de meio século, pela boca profética de seu Zaratustra, embora não pudesse em sua visão genial, nem de longe prever o alcance e a amplitude, ou o módulo acelerado dessa revolução total em que se debate, angustiado e como que perdido, o espírito humano. O certo é que tudo se desmorona, ao embate incessante de novas forças incontroláveis. Daí, o brado emocionante de Paul Valéry - "Nós, civilizações, agora sabemos que também somos mortais".

Aqueles que desejam a solução pacífica dos angustiantes problemas da sociedade moderna, às vezes se atemorizam com o vaticínio dos estu- 
diosos sobre o que nos reserva o futuro. Segundo certos futurólogos, estamos às vésperas de profundas transformações sociais, de consequiências mais radicais e terriveis do que as produzidas pelas revoluções francesa e bolchevista, aquelas que ainda mais nos impressionam, pela proximidade da época em que eclodiram. Viveremos a era tecnotrônica, da tecnologia dominada pela eletrônica. Desgraçadamente, Brezenski, da Universidade de Colúmbia (Estados Unidos) prevê que os sociólogos dos anos 2.000 acharão Robespierre e Lenine moderados, em comparação aos chefes da Nova Era. Tudo isto poderá ser feito, todavia, de maneira pacífica, sem violência. Mas, para isto, principalmente os que dirigem, deverão praticar a justiça, não permitirem o favoritismo, se oporem ao terror, físico e moral, não buscarem o enriquecimento ilícito, (pois existem benefícios abençoados pela lei, mas amaldiçoados pela moral), serem, ao mesmo tempo tolerantes e severos, tolerantes para com os outros e severos para consigo mesmos, mais orientando que punindo, nas primeiras faltas. A justiça e a retidão de caráter nos devem colocar nesta estrada, longe do chão batido pelo homem sem ideal.

1) Não é possivel que permaneçamos todos nós de braços cruzados, face a uma população carente de educação, de recursos elementares de saúde, de compreensão, de paz social, com um crescimento displástico e anárquico de nossa população, onde os ricos não sentem ou, então, não querem sentir os "problemas" do pobre. O discurso de posse do presidente John Kennedy fala bem alto: "Se a sociedade livre não conseguir ajudar os muitos que são pobres, não poderá, igualmente, salvar os poucos que são ricos". A educação deve ter uma finalidade social, que proporcione o bem-estar do povo, de modo a satisfazer a necessidade de todos e não os prazeres, o luxo e o vício de pequeno número de privilegiados, cujas vidas comumente, pela ostentação e desperdício, constituem verdadeiro insulto à pobreza, à quase miséria, de uma grande maioria.

Multidōes aflitas, desesperadas, pedem casas, comida, roupas, saneamento, remédios, ensino, comunicações fáceis. Por isto, a ciência não pode ser divertimento, mas trabalho organizado.

Pedimos educação, saúde e medicina para todos e não para uma minoria de privilegiados. Tudo deveremos fazer para conter o gigantismo das áreas metropolitanas, procurando eliminar a miséria, mitigar a ignorância, a violência e a subnutrição que se aliam a uma desagregação social e cultural profundas, contribuindo para dar saúde ao Homem, que é e continua a ser a primeira riqueza de uma Nação. Herophilos, 300 a.C. já afirmava: "Quando falta a saúde, a sabedoria não se revela, a arte não se manifesta; a força não luta; a riqueza é inútil e a inteligência inaplicável".

2) Quando uma coletividade é composta de elementos fracos, que não sabem lutar, ela conseqüentemente só saberá obedecer ao Estado, que é, e sempre será uma oligarquia. 
3) A educação, o elemento étnico e a boa Terra se imbricam como "telhas de um telhado". A educação - intelectual, moral, cívica e religiosa é o mais forte fator de civilização. É o método prático de se fazer homens saudáveis. E o físico é como um terreno inculto onde se vai plantar. Por sua vez, o progresso da civilização está na razão direta do aumento do trabalho.

Plantando-se, pastoreando o gado, estaremos armazenando um grande capital, uma fortuna enorme. Capital, meus amigos, é o trabalho armazenado. Quando o elemento nacional é incapaz, o mesmo é substituído pelo estrangeiro forte. Devemos, pois, aceitar aquele sábio conselho de George Washington: "É loucura esperar de uma Nação favores desinteressados de outra; tudo quanto uma Nação receber como favor, terá de pagar mais tarde, com parte de sua independência".

Urgem medidas de ordem política, social e econômica para melhorar as condições de vida do povo brasileiro. Não podemos mais conviver, também, com o "patriotismo indolente" que caracteriza grande parcela de nossa população.

Mudanças terão que se processar num pais como o nosso que é plural por sua própria natureza e unitário por sua destinação histórica. Um grande brasileiro referiu, com razão, que estamos plenamente habilitados para aqui instaurarmos uma Democracia Social, com base na realidade da maior Democracia Racial da história, a fim de podermos superar os antagonismos sociais e econômicos, sem incidirmos no erro de confundir "socialização" com "estatização". Socializar, no sentido autêntico desta palavra, significa tornar o povo, em geral, partícipe do progresso e não transferir os meios de produção para o Estado. É somente graças a uma pluralidade de progressos sociais e políticos, através de um modelo cuja configuração eu não saberia dizer-vos, que lograremos integrar na civilização o espaço vital representado por nosso vasto território, sobre cujas riquezas atuais e potenciais só a nós nos cabe decidir. Com esperança, aguardemos por dias melhores. Assim Deus 0 permita.

O espírito divino dorme nas pedras, respira nas plantas, movimenta-se nos animais e fala pela voz do homem. Fala para engrandecer o Criador, fala para penitenciar-se muitas vezes, para encorajar os seus semelhantes, para proclamar a verdade, para dar justiça aos injustiçados, mas também para expressar reconhecimento e gratidão. Nesta hora de tantas alegrias, só nos resta agradecer as manifestações de simpatia e de apreço da Escola de Enfermagem contraindo convosco o compromisso moral de tudo envidar para corresponder à vossa confiança, tão belamente concretizadas na dádiva faustosa com que confundís nossa pequeneza.

Que Deus transmude o impulso magnânimo de vossa generosidade em bençãos que caiam sobre vós, sobre a paz de vossos lares, pela mercê que nos fazeis, na bendita expressão dos vossos mais belos e nobres sentimentos. 
Amanhã, nos hospitais ou nos laboratórios, voltaremos às nossas lutas, elevando a Medicina e a Enfermagem naquilo que elas têm de mais substancial - o amor ao trabalho, o culto desinteressado à sua ciência, o devotamento e o respeito ao doente e a observância à magnitude de sua função social.

A homenagem que acabo de receber da Escola de Enfermagem saberei agasalhá-la e querer-lhe tanto como as rosas-de-sol colhidas ao longo dos meus caminhos.

Prof. Dr. Carlos da Silva Lacaz 